\title{
Ações e Reflexões Vivenciadas por uma Professora em Formação Inicial por Meio de Elaboração de Planos e Regência de Aulas: Contribuições do Processo de Reflexão Orientada
}

\section{Teaching Actions and Reflections Experienced by a Pre- Service Teacher during Elaboration Plans and Classes Practice: Contributions of Oriented Reflection Process}

\author{
Raniele Aparecida da Silva ${ }^{(0)}$ Brasil \\ Francislainy Natália da Silva ${ }^{\circledR}$ Brasil \\ Rita de Cássia Suart ${ }^{\circledR}$ Brasil
}

Esta pesquisa apresenta ações, reflexões e discussões vivenciadas por uma professora em formação inicial, durante a elaboração e a regência de uma sequência de aulas, baseada na abordagem do Ensino por Investigação. Com os resultados, percebe-se que a professora em formação inicial apresenta dificuldades em apresentar elementos essenciais da abordagem do Ensino por Investigação em seus primeiros planos de aula, e, a partir das discussões e sugestões realizadas durante os encontros do Processo de Reflexão Orientada (PRO) a professora em formação inicial evidencia uma evolução na reelaboração de seus planos, que passam a apresentar características do Ensino por Investigação. Os resultados também mostram a importância do grupo, e da professora formadora no processo de reflexão vivenciado, pois, as discussões, sugestões e reflexões realizadas possibilitou que ela valorizasse suas ações durante sua regência, e identificasse o que precisava de aperfeiçoamento em sua prática docente.

Palavras-chave: reflexão orientada; plano de aula; formação inicial.

This research presents actions, reflections and discussions experienced by a pre-service teacher during the elaboration and development of a lesson's sequence based on the investigative teaching approach. With the results it is possible to notice that the preservice teacher demonstrated difficulties while presenting essential elements of the investigative teaching approach in her first class planning. Then, through the discussions and suggestions given during the meetings of Oriented Reflection Process (PRO), the pre-service teacher showed an evolution on the other lesson's plans, that started presenting inquiry teaching features. The results also show the importance of the group in the reflection process, since through the discussions, suggestions and reflections, she began to value her actions and identifying what was needed to improve her teacher practice.

Keywords: oriented reflection; class planning; pre-service teacher. 


\section{Introdução}

É de extrema importância que, ao ensinar os conceitos relacionados à disciplina de Química, os professores proporcionem momentos e ações para que os estudantes possam desenvolver competências e habilidades, tornando-se, cada vez mais, capazes de compreender e tomar decisões sobre os mais diversos problemas que a sociedade tem vivenciado. No entanto, ensinar Química no Ensino Médio é um grande desafio para os professores, pois os conceitos relacionados a essa disciplina são, em sua maioria, abstratos, fazendo com que os alunos apresentem dificuldades em perceber a sua relação com o cotidiano, o que pode tornar a Química um componente curricular considerado difícil e sem sentido, envolvendo, muitas vezes, a memorização de conceitos e aplicação de equações químicas (Fernandez, 2018; Wartha \& Faljoni-Alário, 2005).

De acordo com Marcondes e colaboradores (2009), para possibilitar que os estudantes relacionem os conceitos com o seu cotidiano, os professores precisam incorporar práticas educativas contextualizadas, que visam à cidadania e não somente o desenvolvimento de conceitos e memorização de equações e fórmulas químicas.

Neste sentido, para que os estudantes sejam mais críticos e atuantes na sociedade, professores e pesquisadores vêm explorando novas abordagens e estratégias de ensino. Uma abordagem que pode ser utilizada é o Ensino por Investigação. Para que os professores desenvolvam essa abordagem nas aulas do Ensino Médio, é essencial que os cursos de formação inicial e continuada de professores, proporcionem não somente a formação de conceitos disciplinares e específicos, mas que promovam momentos para que eles possam pensar e repensar sua prática docente de maneira mais crítica (Suart \& Marcondes, 2018).

Esses momentos podem ser proporcionados pelo Processo de Reflexão Orientada (PRO), o qual oferece a oportunidade ao professor de compreender seu papel formativo, buscando maneiras de aperfeiçoar e melhorar sua prática docente (Suart \& Marcondes, 2018; Oliveira \& Serrazina, 2002). O processo de reflexão pode acontecer em grupo, onde os professores em formação inicial ou continuada colaboram na identificação e interpretação de suas ações; ou de forma individual, por meio de um diário de campo. Ao escrever no diário, o professor tem a oportunidade de recuperar imagens e lembranças que passaram despercebidas, realizando uma revisão e análise das ações ocorridas (Zabalza, 2004).

Dessa forma, esta pesquisa teve por objetivo investigar como a participação de uma professora em formação inicial em Química, em um grupo de reflexão orientada, contribuiu para uma formação mais crítica e reflexiva sobre a sua prática docente. Para isso, consideramos necessário investigar as seguintes questões: Como a professora em formação inicial elabora e reelabora seus planos de aulas? Quais reflexões a professora em formação inicial realiza sobre as discussões em grupo e com a professora formadora no grupo de reflexão? Que reflexões ela realiza antes e após a regência das aulas? 


\section{Fundamentação Teórica}

Desde os meados do século XIX, a inserção de atividades de caráter investigativo nas aulas de ciências vem sendo defendida. No entanto, o ensino proporcionado pela Educação Básica, na maioria das vezes, ainda é pautado na transmissão de conceitos, onde o professor é responsável por abordar um conteúdo já selecionado, e aos estudantes cabe apenas o papel de memorizar e armazenar o que foi transmitido pelo professor (Cachapuz et al., 2002).

Buscando uma educação que promova a formação de estudantes mais críticos e atuantes na sociedade, pesquisadores do ensino de Ciências vêm explorando novas práticas de ensino, dentre elas, a abordagem de Ensino por Investigação (Zômpero, et al., 2017; Carvalho, 2013; Zômpero \& Laburú, 2011). Nessa abordagem, a participação dos estudantes é priorizada, permitindo que eles argumentem, compreendam e enfrentem os mais diversos problemas do cotidiano, de forma a possibilitar que consigam tomar decisões que envolvam ideias e conceitos relacionados à Ciência, Tecnologia, Sociedade e Ambiente (Freire, 2014; Maldaner, 2013; Sasseron \& Carvalho, 2008).

Zômpero e Laburú (2011) analisaram os pressupostos do Ensino por Investigação com base em estudos de diferentes abordagens e autores, ressaltando que atividades desta natureza devem partir sempre de situações problemas. Essas situações podem ser levantadas tanto pelos alunos quanto pelos professores, sendo de fundamental importância que "os alunos se interessem pelo problema a ser investigado, de forma a serem motivados a resolvê-lo" (Zômpero \& Laburú, 2011, p. 75). Ao explorar maneiras de solucionar a questão problema, os estudantes podem vivenciar momentos de discussões e buscar resoluções para um determinado problema proposto, estabelecendo relações entre variáveis para explicar determinado fenômeno, utilizando, também, de suas próprias deduções e hipóteses (Solino, 2017; Sasseron, 2015).

A abordagem do Ensino por Investigação contribui para que os alunos interpretem e analisem de maneira crítica as informações que são apresentadas pelo professor, para que, posteriormente, elaborem hipóteses, levando-os a construção do conhecimento (Carvalho, 2018; Nascimento \& Gomes, 2018; Zômpero \& Laburú, 2011). Sendo assim, acredita-se que desenvolver atividades baseadas na perspectiva do Ensino por Investigação no contexto escolar, possibilitará que o aluno seja autor do seu próprio conhecimento, além de se tornar um cidadão mais crítico e reflexivo.

No entanto, planejar, elaborar aulas e materiais didáticos baseadas no Ensino por Investigação não é simples. É essencial que os espaços de formação docente proporcionem aos futuros professores a participação em processos formativos que contemplem discussões e reflexões sobre novas estratégias e abordagens de ensino, bem como, a elaboração, a aplicação, a avaliação e a reflexão sobre novas atividades e materiais didáticos (Suart et al., 2018; Miranda et al., 2015).

A fim de possibilitar uma maior aproximação entre teoria e prática, e contemplar as relações e individualidades do processo de ensino e aprendizagem na formação inicial, assim como, o desenvolvimento de profissionais mais críticos, pesquisadores 
da área de Ensino de Ciências, defendem a formação reflexiva dos professores (Moate, et al., 2019; Suart \& Marcondes, 2018; Maldaner, 2013; Alarcão, 2011). Um professor reflexivo não é um mero reprodutor de metodologias e abordagem, mas sim, aquele que é capaz de analisar criticamente sua própria prática docente. Uma prática baseada na reflexão, permite maior autonomia para os professores, oferecendo oportunidades para seu desenvolvimento através da investigação de sua prática docente, das metodologias utilizadas e da relação que desenvolve com os estudantes (Alarcão, 2011; Oliveira \& Serrazina, 2002).

Ao participar do processo de reflexão, o professor pode revisitar suas experiências de ensino, possibilitando que ele repense, analise e avalie suas ações, de forma a buscar alternativas para alcançar melhores resultados no futuro. A reflexão pode ser compreendida como uma resposta a ações já realizadas que permitem novas avaliações e tomadas de decisão, que levam ao planejamento e execução de novas ações (Kayapinar, 2018; Burhan-Horasanli \& Ortaçtepe, 2016).

O processo de reflexão pode acontecer de forma individual, ou em grupo. Durante o processo de reflexão individual, o professor tem autonomia e privacidade de autoavaliar-se, identificando dilemas e dificuldades enfrentadas durante a atividade docente (Zabalza, 2004).

Para a reflexão individual, um instrumento que pode ser utilizado pelos professores é o diário de campo. Através do diário, o professor é incentivado a refletir sobre sua prática e estratégias em dois momentos; inicialmente, pela escrita e logo após, pela reflexão sobre o que foi escrito (Barreiros \& Gianetto, 2015; Zabalza, 2004). Através das reflexões que o docente, ou futuro docente registra em seu diário, é possível desenvolver justificativas e possíveis soluções para os dilemas enfrentados, colaborando para que o professor, ou futuro professor, aperfeiçoe sua prática docente.

$\mathrm{Na}$ reflexão em grupo, os professores contribuem para a identificação e interpretação de suas ações e, também, na interpretação das ações de outros professores. Nesse momento, o professor pode ainda, compartilhar seus medos, receios e inseguranças, suas concepções e individualidades sobre a ação docente, possibilitando que todo o grupo analise de forma crítica, sua aula, planos de aulas, postura e materiais didáticos. Assim, o professor pode compreender suas próprias ações possibilitando que ele busque maneiras de aperfeiçoar sua prática (Suart \& Marcondes, 2018; Peme-Aranega et al., 2009; Oliveira \& Serrazina, 2002).

Para fomentar o desenvolvimento do processo de reflexão e contribuir para as discussões em grupo, uma proposta que pode auxiliar os professores em formação inicial e continuada, é o Processo de Reflexão Orientada (PRO). Para Abell \& Bryan (1997) o PRO pode ser desenvolvido através de quatro contextos: 1) reflexões sobre outras práticas de ensino: experiências e situações de ensino são analisadas e confrontadas, bem como, sobre concepções de ensino e aprendizagem; 2) reflexão sobre a opinião de educadores: a partir de artigos e aprofundamento teórico os professores em formação inicial confrontam diversos pontos de vistas; 3 ) reflexão sobre si mesmo: o professor 
pensa a respeito de seus conhecimentos, o conteúdo que ensina e também acerca dos conceitos que norteiam o ensino de Ciências; 4) reflexão em relação a sua própria prática: o docente analisa sua prática e ações na sala de aula.

Nesse contexto e através da mediação de um professor formador, o processo de reflexão orientada possibilita que o docente compreenda a si próprio, de forma a pensar e repensar sua prática e ações de forma mais crítica, e orientada (Suart \& Marcondes, 2018; Peme-Aranega et al., 2009). O professor mediador irá ajudar no processo reflexivo dos professores em formação inicial ou continuada, de forma que possam melhorar as suas práticas docentes, por meio da mediação nas discussões de referenciais teóricos, nos encontros que são realizados em grupos ou em atendimentos individuais.

Ainda, no processo de reflexão orientada, professores em formação inicial e continuada têm a oportunidade de elaborar e avaliar suas ideias e ações assim como, pensar na elaboração, aplicação, avaliação e a reflexão de novas atividades, possibilitando a eles compreenderem suas crenças e concepções sobre o processo de ensino e aprendizagem (Suart \& Marcondes, 2018).

\section{Aspectos metodológicos da pesquisa}

A pesquisa apresenta características de uma abordagem qualitativa, baseada na pesquisa ação (Tripp, 2005). A professora em formação inicial ${ }^{1}$, ao participar do processo de reflexão orientada, planeja, descreve e, também, investiga sua própria prática docente. Por meio das intervenções realizadas pela mediadora, ela busca superar suas dificuldades e aperfeiçoar sua prática docente, refletindo sobre seus materiais, atividades e ações durante a regência de aulas. Apresentamos as ações e vivências relacionadas a uma sequência de aulas elaborada e desenvolvida em contexto real de sala de aula, durante a participação de uma professora em formação inicial, uma das autoras deste trabalho, em um grupo de reflexão orientada.

O grupo era formado por cinco licenciandos em formação inicial (L), uma professora da rede pública $(\mathrm{PR})$ de ensino e uma professora formadora (PF) do curso de Licenciatura em Química, de uma Universidade Mineira. Os encontros do grupo aconteciam semanalmente, e, nesses encontros, eram realizadas discussões, leituras e reflexões relacionadas a metodologias de ensino e à prática docente, assim como, discussão de conceitos químicos que estariam presentes na sequência de aulas (SA).

Nos primeiros encontros do grupo de reflexão orientada, a professora formadora responsável por mediar às discussões, orientou a todos os participantes do grupo que utilizassem um diário de campo, onde poderiam realizar reflexões sobre as discussões realizadas no grupo, sobre sua própria prática e sobre a prática docente dos outros professores do grupo, também em formação inicial.

A sequência de aulas foi desenvolvida na perspectiva da abordagem do Ensino por Investigação (Carvalho, 2018; Solino, 2017; Zômpero \& Laburú, 2011), e ministrada

1 Para conferir maior fluidez ao texto, alternamos a utilização dos termos professora em formação inicial e futura professora, mas ressaltamos que, estamos nos referindo ao mesmo sujeito de pesquisa. 
a estudantes do segundo ano do Ensino Médio de uma escola da rede pública. Para a construção e reflexão sobre o desenvolvimento da sequência de aulas, foram realizados dezesseis encontros em grupo. Em treze desses encontros, aconteceram discussões de referenciais teóricos para fundamentar a elaboração e reelaboração da sequência.

Um encontro foi realizado para a discussão sobre a elaboração dos três primeiros planos de aula propostos pela professora em formação inicial, que ministraria a sequência na escola parceira. Os três planos foram elaborados de uma única vez, e discutidos com a professora formadora e o grupo. Após as discussões, a professora em formação inicial repensa e reelabora os planos, para ministrar a SA. Dois encontros foram realizados após a regência de todas as aulas, para que a professora em formação inicial relatasse sua experiência e vivência, assim como, refletisse sobre sua prática docente, repensando o que poderia ter feito diferente na sequência. Esses encontros também possibilitaram que a professora da rede pública e os outros licenciandos pudessem fazer sugestões para melhorias nas aulas.

A sequência contemplava sete aulas e tinha o propósito de construir, juntamente com os alunos, conteúdos relacionados ao desenvolvimento do conceito de Mol. A professora em formação inicial, foi escolhida, pois conseguiria ministrar todas as aulas na escola parceira. Ainda, foi à primeira oportunidade para ela vivenciar na prática a realidade encontrada na sala de aula. A descrição das aulas da sequência final, proposta pelo grupo, encontra-se a seguir:

Primeira aula: tinha o propósito de investigar as ideias prévias dos estudantes. Para isso, uma situação problema em forma de História em Quadrinhos (HQ) seria apresentada aos alunos. Após, a leitura, uma roda de conversa seria formada para discussão da situação problema, que envolvia o incidente da empresa fictícia responsável pela fabricação de um medicamento semelhante ao Celobar ${ }^{2 \circledR}$;

Segunda aula: nesta aula, através do estudo sobre as Unidades do Sistema Internacional de Medidas, a futura professora deveria possibilitar aos alunos compreenderem que, para medir cada grandeza, uma unidade de medida seria "adequada", assim como, compreenderem que as unidades mais utilizadas no dia a dia, não seriam apropriadas para quantificar número de moléculas, átomos e partículas;

Terceira aula: a partir de um diálogo com os alunos, a professora em formação inicial desenvolveria os conceitos relacionados à constante de Avogadro. Em seguida, definiria a constante de Avogadro, questionando os alunos sobre a relação da constante com as aulas anteriores;

Quarta aula: nesta aula foi proposto o desenvolvimento das relações existentes entre massa molar e a constante de Avogadro. Ainda, a professora, juntamente com os alunos, calcularia a massa molar das substâncias da reação do caso Celobar ${ }^{\circledR}$;

2 O caso Celobar está relacionado ao incidente que ocorreu em 2003 e ocasionou a morte de 20 pessoas após a ingestão do medicamento para a realização de exames de contraste. Para maiores informações consultar Tubino M. \& Simoni J. A. (2007). Refletindo sobre o caso Celobar ${ }^{\varpi}$. Química Nova na Escola, 30(2), 505-506. 
Quinta aula: nesta aula, a professora iria construir com os alunos o conceito de reação química, demonstrando diferentes maneiras para expressar uma reação química, utilizando, por exemplo, unidades de medidas e expressões matemáticas;

Sexta aula: continuando as discussões sobre diferentes maneiras para expressar uma reação, a professora apresentaria as reações utilizando um simulador computacional;

Sétima aula: uma nova situação problema seria apresentada aos alunos, que deveriam apresentar possíveis soluções para a problemática por meio da elaboração de um texto argumentativo.

Após a construção da SA, e antes da regência das aulas, um encontro foi realizado para o grupo discutir sobre a elaboração dos três primeiros planos de aula pela professora em formação. Nesse encontro, a professora em formação inicial apresentou os planos propostos para as três primeiras aulas ao grupo, e sugestões e reflexões foram realizadas para que ela pudesse reelaborar os planos, de forma a contemplar as expectativas planejadas, ou seja, aulas com características de uma proposta de Ensino por Investigação. No entanto, a futura professora não teve a oportunidade de apresentar os outros planos de aula elaborados ao grupo, visto que as aulas aconteceram em um restrito intervalo de tempo, o que impossibilitou a realização de novos encontros do PRO.

Os planos elaborados pela professora em formação inicial apresentavam a seguinte estrutura, conforme orientado pela professora formadora: objetivo; objetivo específico; justificativa; conteúdo; recursos; desenvolvimento da aula; avaliação; competências e habilidades contempladas na aula e bibliografia. Na apresentação dos resultados, os planos de aulas serão denominados por PA seguidos do número que representa a aula. É importante destacar que a regência da SA, e, também, os encontros do PRO, foram registrados em áudio e vídeo.

Para compreender como a reflexão contribuiu para o processo de formação da futura professora, é essencial investigar as ações desenvolvidas por ela, através dos quatros contextos do processo da reflexão orientada propostos por Abell e Bryan (1997):

Reflexões sobre práticas de ensino e opinião de outros educadores (contextos 1 e 2): as ações realizadas nesses contextos estão relacionadas aos treze primeiros encontros do processo de reflexão, em que ocorreram discussões sobre o uso do diário de campo reflexivo, estudos sobre o conceito de Mol e, ainda, diferentes abordagens de ensino que poderiam contribuir para o aprendizado dos estudantes, sendo uma delas, a abordagem do Ensino por Investigação. Esses contextos não são focos das análises desenvolvidas nessa pesquisa, entretanto, estão diretamente relacionados ao processo de formação da futura professora, pois influenciaram a construção de seus planos e ações para suas aulas.

Neste sentido, os planos elaborados pela professora em formação inicial, foram analisados a fim de investigar se ela considera, e de que forma ela considera, os aspectos teóricos e outras experiências de ensino discutidos nos encontros do grupo, ou seja, se ela leva em conta, por exemplo, a presença de elementos pedagógicos essenciais do 
Ensino por Investigação para propor e desenvolver seus planos de aula, e quais as ações ela planeja para desenvolver os conceitos com os estudantes.

Reflexão sobre si mesma e reflexão sobre sua própria prática (contextos 3 e 4): ao discutir sobre seus planos de aula com o grupo, a futura professora teve a oportunidade de pensar e repensar sobre si mesma, considerando seus conhecimentos específicos sobre o conceito que planejava ensinar, sobre as habilidades que desejava construir com os estudantes e quais os objetivos almejava alcançar nas aulas.

Nesses momentos, a professora em formação inicial teve a oportunidade de refletir sobre suas ações após a elaboração e reelaboração dos planos de aulas, durante e após a regência das aulas da SA, de forma individual, em seu diário de campo e, também, de forma coletiva, nos encontros com o grupo de reflexão.

Os dados para esta pesquisa foram obtidos por meio dos planos de aula elaborados pela futura professora, pelas reflexões realizadas por ela em seu diário de campo; antes, durante e após a elaboração dos planos e regência das aulas, das gravações das aulas ministradas e das discussões realizadas nos encontros do grupo de reflexão orientada, os quais foram gravados e transcritos.

As diferentes fontes de dados foram submetidas à análise de conteúdo proposta por Bardin (2016). As análises foram realizadas em quatro etapas: 1) Análise exploratória, por meio do qual os planos, as reflexões e os vídeos foram analisados de forma a conhecer, ainda que superficialmente, algumas informações; 2) Tratamento do corpus da pesquisa, por meio do qual as informações foram selecionadas; 3) Organização das informações, de forma a contemplar as evoluções na construção dos planos pela professora em formação inicial, na regência e nas reflexões, de acordo com os seus elementos pedagógicos constituintes, ou seja, objetivos, desenvolvimento, questão problema, questões realizadas durante a aula e sistematização, evidenciando os dilemas vivenciados, as reflexões sobre a prática docente e aquelas manifestadas nas reuniões de grupo; 4) Por fim, realizou-se a interpretação e a inferência dos dados.

Todos os planos de aulas foram analisados individualmente pelos integrantes do grupo de reflexão orientada, assim como os vídeos da regência das duas primeiras aulas, e o diário de campo elaborado pela professora em formação inicial durante o processo formativo relacionado às duas primeiras aulas da SA. Após as análises individuais, os resultados foram discutidos e validados em um encontro do grupo de reflexão. As diferentes fontes de coleta de dados e as discussões e análises realizadas por diferentes pesquisadores possibilitaram uma triangulação e validação das análises.

Assim, após esse processo, alguns excertos foram selecionados, os quais nos permitem responder às questões de pesquisa e evidenciar as contribuições do processo reflexivo vivenciado pela futura professora. Os excertos dos primeiros planos de aula e dos planos reelaborados pela professora em formação inicial foram selecionados de forma a demonstrar as principais modificações realizadas por ela, o que exibe as contribuições do grupo de reflexão e da professora mediadora do grupo. Os trechos do diário de campo foram escolhidos para explicitar seus conflitos, dilemas e as dificuldades 
encontradas durante a elaboração e regência da SA.

Por fim, os excertos das reuniões e das reflexões realizadas após as discussões em grupo foram selecionados a fim de exibir as contribuições do grupo e da professora formadora e mostrar como a professora em formação inicial reflete sobre essas discussões. Para evidenciar as análises, apresentamos alguns excertos nas discussões dos resultados.

\section{Resultados e discussões}

O grupo havia proposto para a primeira aula, apresentar aos estudantes, a questão problema por meio de uma história em quadrinhos. Após a leitura da HQ, seria formada uma roda de conversa, e esperava-se que os estudantes apresentassem hipóteses e soluções para explicar os possíveis erros cometidos pela empresa durante o processo de fabricação do medicamento semelhante ao Celobar ${ }^{\circledR}$. No encontro para reflexão e discussão sobre a elaboração do plano para a primeira aula, a professora em formação inicial apresentou seu planejamento ao grupo, destacando como desenvolveria o conteúdo e quais estratégias utilizaria nas aulas. A futura professora apontou como o objetivo, em seu plano de aula (PA1):

"Construir, juntamente com os alunos, os conceitos de quantidade de matéria, massa molar e molecular, destacando a importância sobre a Constante de Avogadro e suas aplicações através de situações do cotidiano.”.

Ao exibir seu plano para o grupo, a professora formadora questiona se o objetivo apresentado para a aula era adequado, pois, o que foi proposto por ela, assemelhava-se ao da SA, e não ao objetivo para a primeira aula. Isso também ocorreu para o objetivo específico e justificativa, que também eram os mesmos apresentados para a sequência de aulas.

Para o desenvolvimento da aula, a professora em formação inicial não apresenta ou menciona a problematização inicial, bem como questões para levantar as concepções dos estudantes e ou para realizar a sistematização da aula, como evidenciado no trecho do seu plano:

"Para iniciar a aula começar questionando os alunos sobre a leitura do texto do Celobar ${ }^{\circledR}$ e em seguida pedir para os estudantes para lerem a história em quadrinho. Após a leitura solicitar que formem uma roda de conversa e discutir sobre a relação dos textos e, também, sobre as dúvidas que os alunos apresentarem durante a roda de conversa”.

A partir dos trechos da proposta apresentada ao grupo, fica evidente a dificuldade que a professora em formação inicial encontra em construir o plano para aula. Além disso, a ela não explicitou em seu plano, elementos essenciais da abordagem de Ensino por Investigação.

Ao encontro das pesquisas realizadas por Maldaner (2013) e Alarcão (2011), essas dificuldades podem estar relacionadas ao seu processo de formação, que priorizou, em sua maior parte, uma formação conteudista e tradicional, e não ofereceu oportunidades para que ela construísse, entre outras habilidades, suas próprias propostas e seus 
materiais didáticos. Ainda, por não apresentar os elementos essenciais do Ensino por Investigação, como a questão problema, sistematização, a professora em formação inicial expõe dificuldades na compreensão da perspectiva dessa abordagem.

Após as discussões ocorridas durante o encontro e com as orientações da mediadora, a futura professora reelabora seu plano e constrói um novo objetivo para a primeira aula. Em seu PA1 reelaborado, foi evidenciado como objetivo:

"Com a leitura de textos norteadores, levantar as ideias prévias dos estudantes e problematizar o incidente ocorrido com o medicamento Celobar ${ }^{\circledR}$, motivando os alunos a compreenderem a importância nas determinações das proporções corretas de substâncias utilizadas em sínteses de medicamentos".

Em seu diário de campo é possível perceber as dificuldades enfrentadas por ela ao construir o plano de aula:

"Foi muito difícil fazer o planejamento das primeiras aulas para sequência. Não sabia por onde começar ou o que levar em conta ao escrever o planejamento, não sabia se deveria detalhar ou apresentar as ações de forma resumida (...). Como já havíamos elaborado o material para a sequência de aula, ao construir o plano de aula não considerei informações essenciais para aula, e ainda apresentei nos planos o mesmo objetivo para a SA (...). Somente após apresentar os planos para o grupo e com as discussões percebi que poderia detalhar mais meu plano, apontando ações específicas para aquela aula. Ao reelaborar o plano, pensei nos objetivos para cada aula, considerando quais conceitos construiria e quais habilidades desenvolveria com os estudantes".

Através da reflexão e discussões proporcionadas pelo PRO e com a orientação da professora formadora, a futura professora pode analisar e refletir de forma crítica sobre o primeiro objetivo elaborado. Assim de acordo com Gil-Pérez e Vilches (2006) a reflexão propiciou uma mudança em sua concepção a respeito do objetivo da aula, possibilitando a ela buscar novos conhecimentos e adequações conceituais e pedagógicas em seu plano de aula.

Para o desenvolvimento da primeira aula, por exemplo, a professora em formação inicial propõe apenas questionar os alunos sobre a leitura da história em quadrinhos. Ao apresentar seu plano durante o encontro reflexivo, a professora em formação inicial é questionada pela professora formadora se haveria o levantamento das ideias prévias dos estudantes, ou seja, uma ação de relevância para a construção de novos conhecimentos que possibilitaria aos estudantes estabelecerem relações entre conceitos científicos e o conhecimento de senso comum. Ao reelaborar o desenvolvimento da aula, foi proposto:

"Solicitar aos estudantes que, primeiramente, formem uma roda. Em seguida, levantar as ideias prévias dos alunos sobre o incidente do medicamento do caso Celobar ${ }^{\circledR}$. E, utilizar algumas questões que possam nortear a discussão, como, por exemplo, o que é exame de contraste, o que é síntese (...)”.

Ao reformular seu plano, a professora em formação inicial repensa o desenvolvimento de sua aula, considerando as sugestões realizadas pela professora 
formadora e pelo grupo, e propõe questões que podem ser realizadas para investigar as ideias prévias dos alunos, um dos elementos essenciais da abordagem do Ensino por Investigação.

Ao idealizar questionamentos para conhecer as ideias prévias dos estudantes, a futura professora está planejando ações para mediar a aula. Além disso, para Mellado (1998) a investigação dessas ideias é essencial para o desenvolvimento de atividades baseadas na perspectiva do Ensino por Investigação, uma vez que, novos conhecimentos podem ser aprendidos a partir de outros preexistentes na estrutura cognitiva do indivíduo, considerando que, para alcançar uma aprendizagem mais significativa, estes conhecimentos precisam ser construídos, desconstruídos e reconstruídos através das discussões, atividades e reflexões que acontecem na sala de aula.

Como orientado pela professora formadora do grupo, após ministrar a primeira aula da sequência, a professora em formação inicial, relata em seu diário as suas impressões, crenças e seus dilemas sobre a aula. No excerto a seguir, percebemos que ela não consegue realizar o que foi planejado para a aula:

"A primeira aula era uma roda de conversa, havia planejado pedir aos alunos que formassem uma roda. Mas aconteceram imprevistos para a organização do material e, também, da câmera, então para não perder mais tempo, preferi deixar os alunos em seus lugares. Comecei então, a questionar os estudantes quanto à leitura do texto do caso Celobar ${ }^{\mathbb{R} ”}$.

Ao confrontar o que foi planejado para primeira aula com os relatos do diário de campo da professora em formação inicial, percebe-se que ela não consegue realizar o que foi planejado. A partir das reflexões realizadas em seu diário, constata-se que durante a aula, aconteceram situações que ela não esperava. Segundo Gauthier et al. (2013) isso implica que, ao elaborar seu plano de aula, a futura professora não propôs ações que pudessem ser realizadas, caso ocorressem imprevistos. No entanto, mesmo não realizando o que havia proposto em seu planejamento, ela não ficou presa ao seu plano de aula, conseguindo, assim, pensar em outras ações no momento da aula.

Para a segunda aula da sequência, foi proposto pelo grupo, o desenvolvimento de conceitos de unidades de medidas utilizadas no cotidiano e, também, abordar as unidades do Sistema Internacional de Medidas. A primeira versão do plano para a segunda aula, elaborado pela professora em formação inicial, apresentava as mesmas dificuldades encontradas no primeiro plano em relação ao objetivo geral, específico e justificativa para a aula, já que se assemelhavam aos que foram propostos para SA.

A professora formadora novamente indaga a futura professora se estes elementos estão adequados. Ao descrever sobre o desenvolvimento da aula, na primeira versão do PA2, ela não apresenta relações dessa aula com a anterior, conforme a transcrição de seu plano:

"Para iniciar a aula, questionar os alunos sobre o que eles conhecem sobre o Sistema Internacional de Medidas". 
É possível perceber que, mesmo que o grupo tenha proposto uma SA com características da abordagem do Ensino por Investigação, ao construir seu plano, a professora em formação inicial ainda considera aspectos de uma abordagem tradicional de ensino, não apresentando questionamentos para retomar as ideias discutidas na aula anterior ou retomando a situação problema, o que evidencia de acordo com PemeAranega e colaboradores (2009) que suas teorias implícitas e explícitas estão em conflito, ou seja, o que é apresentado na teoria - no planejamento da SA - não está relacionada à sua prática - seu plano de aula.

Após o encontro do PRO, a futura professora reelabora seu plano de aula (PA2), realizando as modificações que foram sugeridas. Ao reelaborar o PA2, foi proposto o seguinte objetivo:

"A partir do Sistema Internacional de Medidas, mostrar aos alunos algumas das medidas padrões utilizadas, destacando que cada unidade se adequa a diferentes situações, mostrando, também, as unidades que mais utilizamos e que estão presentes em nosso dia a dia”.

Ao construir o desenvolvimento ela considera as sugestões realizadas pelo grupo e planeja:

"Para iniciar a aula retomar as ideias principais discutidas na roda de conversa. Em seguida, questionar os alunos sobre o que eles conhecem sobre o Sistema Internacional de Medidas (...). E, para finalizar, solicitar aos estudantes que resolvam os exercícios presentes no material do aluno, de forma individual em um primeiro momento. $\mathrm{E}$ depois resolver o exercício com os alunos, retomando os principais conceitos discutidos na aula, e relacionar as unidades de medida com a questão problema apresentada na aula anterior".

O encontro do grupo de reflexão orientada motivou a professora em formação inicial a repensar sua aula e seu planejamento, para que ela conseguisse construir ações em seu plano de aula, que a permitisse atingir os objetivos propostos. É importante destacar a importância das discussões e sugestões realizadas durante o encontro processo de reflexão orientada, uma vez que as propostas realizadas possibilitaram que a futura professora repensasse seu plano, planejando a retomada das ideias desenvolvidas na primeira aula. Ao reconstruir seu plano, ela ainda menciona a questão problema e propõe realizar a sistematização dos conceitos desenvolvidos durante a aula.

Ao relacionar o plano de aula elaborado para a segunda aula, com as reflexões descritas em seu diário, é possível perceber que a professora em formação inicial consegue realizar o que foi planejado e que nenhum imprevisto ocorreu durante a regência da segunda aula. As reflexões de seu diário estão relacionadas, em sua maioria, à participação dos alunos e sua postura em sala de aula, conforme o excerto:

"Nessa aula consegui perceber que mais alunos participaram. Apenas quatro alunos não colaboraram com as discussões. Ao deixar determinado tempo para a realização das atividades, os alunos que ainda não haviam participado das discussões, demonstraram interesses em fazer os exercícios. (...) Fiquei um pouco intimidada com os estudantes, 
e acabei ficando em apenas um local da sala. Com as próximas aulas espero estar mais segura e me movimentar mais. Acredito que tenho muito a melhorar, com relação a timidez, a postura, com a segurança dentro da sala de aula".

A partir do excerto acima, é possível perceber que, ao escrever em diário de campo, a professora em formação inicial pensa e repensa as ações realizadas durante a aula, ou seja, reflete sobre sua prática, e descreve aspectos que ainda precisa aprender e melhorar com relação à sua postura. Com base nestas reflexões e nas ideias propostas por Bryan e Recesso (2006), nota-se o aprendizado e o amadurecimento pessoal e profissional da futura professora, levando-a a compreender de forma crítica o processo de ensino e aprendizagem, bem como sua prática docente. Ainda, em seu diário ela relata:

"Durante a aula tentei ao máximo questionar os estudantes e oferecer tempo adequado para eles responderem as perguntas".

Em diversos momentos do processo de ensino e aprendizagem, faz-se necessário interrogar os alunos como, por exemplo, durante a apresentação de novos conteúdos, para revisar conceitos vistos nas aulas anteriores, contribuindo para despertar o interesse e motivar os estudantes durante a aula. É importante que durante as perguntas, o professor possibilite que todos os estudantes tenham a oportunidade de responder aos questionamentos. Ao realizar as perguntas é necessário que o professor faça uma pausa adequada quando os indaga, oferecendo tempo para que eles possam pensar para responder os questionamentos (Gauthier et al., 2013).

Para a terceira aula da SA, foi proposta a construção dos conceitos relacionados à constante de Avogadro. O plano elaborado pela professora em formação inicial, para esta aula, também foi discutido durante um encontro do PRO. No entanto, as dificuldades apresentadas por ela são semelhantes às dificuldades apresentadas nos planos anteriores. Essas dificuldades podem estar relacionadas a falta de aprofundamento teórico e de conhecimento sobre os conceitos que seriam ensinados, e, dessa forma, a futura professora consegue evidenciar o objetivo e o desenvolvimento para cada aula, se apropriando dos que foram propostos para a sequência de aula.

Novamente, a partir das discussões realizadas no PRO, e com as orientações da professora formadora, a professora em formação inicial reelabora seu plano, pois o objetivo e a justificativa são os mesmos da sequência de aula. Ao reelaborar seu plano para a aula, a professora em formação, já não apresenta os elementos gerais da SA. Em seu PA3, ela propõe como objetivo:

"Construir, juntamente com os alunos, os conceitos de Quantidade de matéria e massa atômica, destacando a importância sobre a Constante de Avogadro e suas aplicações através de situações do cotidiano".

Para o desenvolvimento da aula é sugerido:

"Iniciar retomando a situação problema e as unidades de medidas do SI."

Assim, a partir do excerto de seu PA3, é possível perceber que o processo de reflexão 
orientada parece ter possibilitado que a professora em formação inicial repensasse e refletisse sobre as ideias relacionadas ao processo de ensino e aprendizagem. Suart e Marcondes (2018) destacam que com as orientações realizadas durante os encontros do $\mathrm{PRO}$, a futura professora tem a oportunidade de confrontar as discrepâncias existentes entre as suas teorias explícitas e implícitas, possibilitando o desenvolvimento de concepções mais adequadas, o melhoramento de sua prática docente e, talvez, até mudanças em suas teorias pessoais. Vale ressaltar que a professora formadora não impõe suas ideias para a professora em formação inicial, mas incentiva discussões e reflexões sobre suas escolhas, proporcionando maior autonomia em suas ações futuras.

A futura professora considera também a retomada das ideias conforme a orientação da professora formadora. Isso evidencia a importância do PRO, pois possibilitou que ela avaliasse e reelaborasse seus planos de aulas de forma crítica, além de propiciar a ela mudanças em sua estratégia de ensino, visto que os primeiros planos contemplavam aspectos de um ensino mais tradicional, como a discussão do conteúdo sem conhecer quais as ideias que os estudantes apresentavam sobre o conceito a ser estudado, e, após as discussões, os outros planos da sequência contemplaram características de um Ensino por Investigação, como o reconhecimento das ideias prévias e a retomada das aulas anteriores.

Para o momento final da terceira aula, a professora em formação inicial construiria:

"Com os alunos os conceitos relacionados a Mol e massa atômica, e para finalizar a aula mostrar a relação entre o conceito de Mol com a situação problema e com as aulas anteriores".

Quando a futura professora propõe para o final da aula mostrar aos estudantes a relação de Mol com a situação problema, e com as aulas anteriores da sequência, ela está realizando uma sistematização. A sistematização do conhecimento faz-se necessária para que o aluno possa explorar, interpretar e aplicar os conceitos em outros contextos e relacioná-los nas aulas seguintes (Carvalho, 2013; Delizoicov et al., 2018).

Por meio das reflexões sobre a regência de sua terceira aula da sequência, a professora em formação inicial relata em seu diário:

"Entreguei o texto sobre a história da constante de Avogadro, e pedi para que os estudantes realizassem a leitura do texto (...). Durante a aula percebi que os alunos que participavam das discussões eram os mesmos que participaram das aulas anteriores. Fiquei preocupada com os estudantes que não estavam participando (...). E fiquei pensando em como fazê-los participar da aula, mas não consegui. Tentei pedir para que os alunos citassem exemplos e mesmo assim os alunos não participaram”.

A partir do trecho acima, é possível perceber que o fato de os alunos não participarem durante a terceira aula incomoda a professora em formação inicial. Isso ocorre, provavelmente, pelo fato de ela participar de um grupo que desenvolve aulas na perspectiva do Ensino por Investigação e, essa participação, é uma das características dessa abordagem de ensino.

Ao construir os planos para as três primeiras aulas da SA, a professora em 
formação inicial encontra dificuldades em apresentar alguns elementos pedagógicos, como o objetivo e justificativa, e, também, em planejar aulas que abordem características do Ensino por Investigação. Essas dificuldades evidenciam que ainda existem conflitos entre a teoria e sua prática docente, ou seja, apesar de participar de um grupo de reflexão orientada e discutir sobre estratégias diferenciadas de ensino, quando planeja suas aulas, a professora em formação inicial apresenta características de uma professora tradicional. Tais dificuldades também foram evidenciadas nos trabalhos realizados por Oliveira \& Tiyomi Obara (2018) e Peme-Aranega e colaboradores (2009).

Como mencionado anteriormente, apenas os três primeiros planos elaborados para a sequência foram apresentados ao grupo e para a professora formadora. Os demais planos elaborados, não foram discutidos durante o PRO. Desta forma, a professora em formação inicial não teve a oportunidade de rever e repensar os planos construídos.

O desenvolvimento das relações existentes entre massa molar e constante de Avogadro e a realização dos cálculos das massas molares foram os conceitos sugeridos para serem desenvolvidos durante a quarta aula. Em seu PA4, é evidenciado como objetivo:

"Construir com os alunos a relação entre a constante de Avogadro e massa molar".

Ressaltando como objetivo específico, ela descreve:

"Identificar a constante de Avogadro; identificar a constante de Avogadro como uma grandeza do Sistema Internacional de Medidas; compreender a relação da constante de Avogadro com a massa molar e o número de mol; calcular massas molares a partir de massas atômicas".

É possível perceber que a professora em formação inicial já não apresenta o objetivo da SA, ou seja, ela apresenta um objetivo adequado para o conteúdo desenvolvido na aula.

A futura professora apresenta para o início da aula:

"Começar a aula questionando os alunos sobre os conceitos das aulas anteriores, revisando sobre mol e constante de Avogadro, bem como as unidades do SI, e discutindo sobre a relação destes conceitos com a situação problema. Em seguida, investigar o conhecimento prévio dos alunos sobre massa molar e massa atômica, incentivando-os a construir as relações com a constante de Avogadro".

Para finalizar a aula a professora em formação inicial planeja:

"Voltar aos conceitos de massa molar e massa atômica, relacionando-os com os conceitos das aulas anteriores (unidades de medidas e, também, com a questão problema)".

A participação no grupo de reflexão orientada possibilitou que a professora em formação inicial refletisse sobre os seus três primeiros planos de aula, contribuindo para que ela analisasse de forma crítica os seus planos iniciais, reconhecendo suas dificuldades, o que auxiliou o desenvolvimento de concepções mais adequadas na construção de novas ações para sua prática. 
A professora em formação inicial buscou melhorar suas ações, e é possível perceber que ela considerou novas perspectivas ao construir os demais planos, destacando características do Ensino por Investigação, como a retomada de ideias, o levantamento de conhecimentos prévios e a realização de uma sistematização no momento final da aula, que não estavam presentes nos primeiros planos. Por meio dessa evolução, fica evidente as contribuições do PRO, pois foi através das discussões, reflexões e sugestões da professora mediadora e do grupo, que a professora em formação inicial conseguiu construir planos mais adequados e que contemplassem elementos da perspectiva de ensino por investigação.

Em seu diário de campo, após lecionar a quarta aula da sequência, a futura professora relata a dificuldade dos alunos com alguns conceitos:

"Durante as explicações de alguns conceitos, percebi que os estudantes apresentaram muitas dúvidas relacionadas a conceitos anteriores ao da SA. E, durante a aula, fiquei em dúvida sobre o que fazer, mas acredito que é melhor voltar e os estudantes aprenderem alguns conceitos de forma efetiva, do que continuar com a matéria e eles não compreenderem os conceitos da SA. (...) Durante a aula, fiquei em dúvida se continuava com o que foi planejado na SA, ou se tentava voltar nos conceitos que os estudantes apresentavam dúvidas. Vou voltar e trabalhar com os alunos de átomos e moléculas. Assim, não irei usar o simulador como planejado inicialmente".

Diante da dificuldade com os conceitos de átomos e moléculas, a futura professora enfrenta o dilema de não saber se continuava com as aulas de acordo com o planejamento, ou se revisava com os estudantes os conceitos de átomos e moléculas. Ao propor o planejamento, ela não esperava encontrar dificuldades com os conceitos já estudados pelos alunos. E, como evidenciado por Gauthier (2013), com o intuito de cumprir o que foi planejado e talvez pelo medo e insegurança por não querer abordar conceitos não estudados, ela segue seu plano de aula, só pensando em mudar suas ações em aulas futuras.

No planejamento realizado pelo grupo, para as aulas cinco e seis, seriam desenvolvidos os conceitos relacionados a reações químicas e as diferentes maneiras de expressá-las. Ainda, o grupo planejou a utilização de um simulador computacional, para trabalhar com reações químicas.

No entanto, conforme já destacado, ao ministrar a quarta aula da sequência, a professora em formação inicial percebeu que os estudantes apresentavam muitas dúvidas com relação aos conceitos de átomos e moléculas. Ao perceber estas dificuldades, a professora em formação inicial mudou o planejamento da SA, e decidiu revisar estes conceitos, resolvendo, juntamente com os alunos, alguns exercícios, e também propondo a retomada de conceitos já desenvolvidos em aulas anteriores.

É importante ressaltar que a futura professora planeja, inicialmente, as aulas cinco e seis de forma separada. Entretanto, devido a um imprevisto ocorrido na escola, as aulas foram ministradas em sequência, o que pode ter impossibilitado uma maior reflexão sobre os acontecimentos da aula. 
Ao elaborar o seu PA5, é descrito como objetivo:

"Construir com os alunos os conceitos de átomos e moléculas, incentivando-os a perceber as diferenças entre estes conceitos".

Destacando como objetivo específico:

"Possibilitar que os estudantes consigam buscar informações na tabela periódica, construir com os alunos a ideia de que as moléculas são formadas por átomos".

Para o momento inicial da aula ela planeja:

"Retomar os conceitos das aulas anteriores, revisando a situação problema do medicamento Celobar ${ }^{\mathbb{1}}$.

E, para o momento final, ela propõe:

"Voltar nos conceitos de átomos e moléculas, relacionando-os com os conceitos das aulas anteriores, e, também, com a situação problema".

No PA5, a professora em formação inicial cita elementos da abordagem do Ensino por Investigação, como a retomada das ideias e realização da sistematização ao final da aula, no entanto, ela não planeja questionamentos para a retomada de ideias e nem apresenta de que forma realizará a sistematização dos conceitos.

No plano para a sexta aula, a futura professora também menciona a retomada das ideias, a situação problema e sistematização dos conceitos, como evidenciado a seguir:

"Iniciar a aula retomando os conceitos das aulas anteriores, retomando a situação problema do medicamento Celobar ${ }^{\circledR}$. Em seguida, questionar os alunos sobre o que é reação química, solicitar exemplos de algumas reações, questionar os estudantes se a síntese do medicamento é uma reação química (...). Para terminar a aula retomar os aspectos discutidos nas aulas, relacionando a aula de reações químicas com as aulas anteriores, e com a situação problema".

Nos fragmentos do plano para a sexta aula da sequência, a professora em formação inicial apresenta algumas questões que podem ser realizadas durante aula, mas ainda, não apresenta ações para realizar a retomada e sistematização dos conceitos.

Em seu diário de campo, após a regência da quinta e sexta aula, ela relata:

"Na primeira aula ((quinta aula)) voltei aos conceitos de átomos e moléculas, mostrando alguns exemplos e, também, pedindo aos alunos que citassem exemplos. Tentei como nas aulas anteriores, fazer com que os alunos participassem, principalmente, aqueles que não haviam participado ainda. (...) Nessa aula, percebi que os alunos estavam desinteressados e agitados, e não consegui prender a atenção dos alunos. Acho que pode estar relacionada com a repetição da matéria. Mas voltar aos conceitos de átomos e moléculas foi necessário, pois durante as aulas anteriores percebi que eles não haviam compreendidos os conceitos. Talvez para próxima aula seja interessante, realizar alguns exercícios com eles, para não ficar uma aula. (...). Após a revisão, voltei a questão problema e comecei a desenvolver as diferentes maneiras de expressar uma reação química”. 
Nessas reflexões percebemos que a professora em formação inicial continua inquieta com a não participação dos alunos durante as aulas. Para Zabalza (2004), ao utilizar o diário para descrever suas reflexões, a professora relata seus conflitos, emoções, dilemas e angústias. A descrição do conflito enfrentado por ela, faz com que ela se envolva na tentativa de descobrir uma possível solução para eles. Dessa forma, a professora em formação inicial repensa sobre novas ações para as futuras aulas, como na possibilidade de desenvolver alguns exercícios com os estudantes para que eles sejam mais participativos.

Em seus relatos, também é possível perceber que a aula não foi realizada como o planejado:

"Havia planejado de fazer a reação do processamento do ferro, também junto com os alunos, mas como estavam agitados pedi que tentassem resolver sozinhos, e que depois iria corrigir. Nesta aula os alunos estavam muito agitados, e perdi bastante tempo organizando a sala, e pedindo silêncio, então, não consegui realizar a correção do exercício e nem fazer um fechamento da aula".

Concordamos com Gauthier e colaboradores (2013) que a agitação dos alunos, e imprevistos que aconteceram durante a regência da quinta e sexta aulas, podem ter contribuído para o nervosismo e ansiedade da professora em formação inicial, colaborando assim, para que a aula não ocorresse exatamente da maneira que foi planejada, e, ainda, auxiliaram para que ela não realizasse a sistematização dos conceitos.

Para a última aula da sequência, uma nova situação problema foi proposta pelo grupo para ser apresentada aos alunos, onde, por meio de um texto argumentativo, eles poderiam apresentar soluções para a nova situação, considerando os conceitos desenvolvidos durante a aula. A atividade final da SA poderia possibilitar aos estudantes confrontarem as ideias iniciais apresentadas na primeira aula com as ideias construídas durante toda a sequência de aulas. A elaboração do texto argumentativo possibilitaria ao professor avaliar de forma individual a construção do conhecimento dos alunos (Carvalho, 2013).

Como objetivo para a última aula, a professora em formação inicial propõe em seu PA7:

"Permitir, a partir da leitura da situação problema final e dos conceitos construídos nas aulas anteriores, que os estudantes consigam aplicar os conceitos desenvolvidos durante a sequência de aulas em outras situações".

Como objetivo específico, é apresentado:

"Identificar a constante de Avogadro; identificar a constante de Avogadro como uma grandeza do Sistema Internacional de Medidas; relacionar a constante de Avogadro com a massa molar e o número de mol; descarte e reutilização de resíduos; utilização de argumentos".

Em seu PA7, a futura professora sugere começar a aula retomando a situação problema inicial e os conceitos desenvolvidos nas aulas anteriores: 
"Questionando os estudantes sobre quais compostos são utilizados na síntese do medicamento Celobar ${ }^{\circledR}$, quais unidades de medidas mais utilizamos em nosso dia a dia, quais dessas unidades são unidades do SI e qual a relação entre a Constante de Avogadro com massa atômica e massa molar".

Em seguida, a professora em formação inicial planeja:

"Ler com os alunos a situação problema final e pedir que eles elaborem uma redação, utilizando os conceitos para responder a situação problema".

Através do excerto do plano de aula, percebe-se que ela não planejou realizar uma sistematização dos conceitos desenvolvidos durante a sequência de aula, e continua apenas mencionando a revisão dos conceitos e retomada da situação problema, sem planejar ações para realizá-las.

Mas, ao investigar as reflexões realizadas em seu diário após a regência da sétima aula, é possível perceber que ela se preocupa com a sistematização que não foi realizada e sugere que uma nova aula seja planejada, em uma possível nova aplicação, para que ocorra um fechamento adequado, como evidenciado no excerto de seu diário de campo:

"O tempo da última aula da UD foi bem apertado, os alunos estavam bem agitados e nervosos, porque a aula foi ministrada no horário da aula de Educação Física. (...) Acredito que outra aula seria necessária no planejamento inicial da sequência de aulas, para que após a elaboração da redação pelos estudantes, eu conseguisse realizar a leitura dos materiais e conseguisse avaliar a aprendizagem, e verificasse quais os conceitos que eles ainda apresentavam dúvidas. Após a leitura do material, seria possível realizar uma discussão com os alunos sobre as situações inicial e final".

Concordamos com Carvalho (2013) que a sistematização do conhecimento possibilita que o aluno explore, interprete e aplique os conceitos em outros contextos. Ainda, através da sistematização, a futura professora poderia ter contribuído para que os estudantes conseguissem perceber a relação entre os conceitos desenvolvidos e as aulas da sequência, possibilita a eles confrontarem suas ideias iniciais com as que foram construídas durante a aula.

A reflexão realizada pela professora em formação inicial, após ministrar a última aula da sequência, permitiu que ela analisasse de forma crítica sua prática docente, ressaltando aspectos que não ocorreram como planejado. De acordo com Suart e Marcondes(2018), Peme-Aranega et al., (2009), Zeichner (2008) e Oliveira e Serrazina (2002), podemos considerar que a reflexão contribuiu para que a professora repensasse sobre o planejamento da SA, sugerindo alterações que pudessem melhorar a aprendizagem do aluno e a sua própria prática docente.

Após a regência de todas as aulas da sequência, um novo encontro do processo de reflexão orientada foi realizado, onde a futura professora relatou ao grupo a experiência vivenciada. Ainda, por meio das transcrições das aulas, realizadas pelos licenciandos do grupo, foi possível realizar sugestões para a reelaboração da sequência e, também, reflexões críticas sobre a regência das aulas. 
No trecho a seguir são apresentados alguns diálogos durante o encontro reflexivo, sobre a regência das aulas:

"PF: O que vocês acharam das aulas?

L1: Eu gostei, por causa dos diálogos, as discussões não ficaram tumultuadas, muitos alunos participaram das discussões.

L2: A partir da análise das transcrições, percebi que muitos alunos participaram de todas as aulas.

L4: Achei interessante que o texto do medicamento Celobar ${ }^{\circledR,}$ foi entregue na aula anterior, antes do início da regência das aulas da sequência. A leitura antecipada dos alunos sobre algumas informações do incidente do medicamento contribuiu para que os estudantes participassem durante a roda de conversa".

Nas reflexões realizadas pela professora em formação inicial em seu diário de campo, percebemos que, em vários momentos, ela menciona a preocupação com a participação dos alunos. No entanto, ao argumentar sobre a regência das aulas, o grupo de reflexão destaca que os estudantes participaram ativamente das aulas. E, apesar de não explicitar em seus planos questionamentos que poderiam ser realizados durante aula, percebemos, pela reflexão do grupo, que ela conseguiu mediar às discussões.

Em outro momento do encontro do PRO, o grupo destaca:

"PF: E a mediação da professora, como foi? O que acharam?

PR: Para a primeira vez que você aplicou uma sequência de aulas, foi ótima.

L4: Achei que a professora conseguiu conduzir muito bem as discussões realizadas nas aulas. Pois, algumas vezes questionamos os alunos, e quando percebemos que eles não vão responder, contamos a resposta para ele. $\mathrm{E}$ a professora conseguiu mediar às discussões sem fornecer respostas prontas para os estudantes.

L1: Ela soube conduzir bem a aula, ela não deixou a sala virar uma bagunça, durante as brincadeiras que os estudantes fizeram, ela manteve a postura.

L4: Quando os estudantes realizavam questionamentos, ela não apresentava uma resposta pronta, ela respondia com outras perguntas".

O grupo sugere também para a professora em formação inicial alguns cuidados com a linguagem durante a aula e a escrita realizada na lousa, para que os alunos não desenvolvam concepções errôneas sobre determinado conceito ou compreendam de forma inadequada as representações que são utilizadas na Química.

Após ministrar todas as aulas e a partir das discussões no PRO, a futura professora continua realizando reflexões sobre a sequência de aulas. E ela relata sobre sua insegurança durante a aplicação das aulas e sobre a importância das análises e reflexões do grupo acerca das transcrições das aulas. 
"Sempre que refletia sobre as aulas, conseguia pontuar vários tópicos que poderiam ser melhorados. E fiquei feliz de saber que, de alguma forma, eles gostaram da aula, ressaltaram pontos positivos como a minha postura e como consegui mediar às discussões e aula (...). As discussões e reflexões realizadas durante o PRO, foram muito importantes, pois conseguir destacar aspectos que não havia percebido durante a aula, e, nem com a leitura da transcrição".

O processo de reflexão proporcionado pelo $\mathrm{PRO}$, possibilitou que a professora em formação inicial revisitasse acontecimentos ocorridos durante as aulas, oferecendo oportunidades para ela desenvolver sua prática docente. As discussões em grupo possibilitaram que ela enxergasse alguns problemas, descobrisse novos caminhos e construísse possíveis soluções. Os licenciandos do grupo também ressaltaram aspectos positivos que foram realizados por ela durante as aulas, possibilitando que a futura professora repensasse e refletisse, com outro olhar, sobre a regência das aulas.

Em outro encontro do processo de reflexão orientada, o grupo discutiu e sugeriu possíveis alterações na sequência de aula. O grupo propõe algumas atividades para revisitar os conceitos de átomos e moléculas:

"L3: Como os alunos apresentaram muitas dificuldades com átomos e moléculas poderíamos pensar em uma atividade experimental ou com tampinhas de garrafas para revisar os conceitos.

PR: Essa atividade poderia ser feita também com massinha de modelar.”

Em outro trecho do encontro, o grupo apresenta propostas para a situação problema final:

"L1: Talvez pudéssemos fazer oito aulas e não sete. Assim, a sétima aula continua sendo uma questão problema final e fazemos mais uma aula, para fazer uma sistematização dos conceitos desenvolvidos durante a sequência de aula. A professora poderia utilizar essa última aula, para dar um feedback aos estudantes sobre as atividades realizadas por eles durante a sequência de aulas. (...)

L2: Podemos planejar um júri químico, onde os alunos vão utilizar os conceitos trabalhados nas aulas, e, também, buscar outras informações para construir bons argumentos."

Ainda, a partir das discussões, o grupo propôs novas atividades para a sequência de aula, e a professora em formação inicial propõe trabalhar com o professor de matemática, como evidenciado no excerto de seu diário:

"A realização do júri pode motivar os estudantes e incentivá-los a participarem das aulas, bem como das outras atividades. (...) Na situação problema final é necessário que os alunos interpretem um gráfico, isso poderia ser desenvolvido com eles em outras aulas. Poderíamos tentar trabalhar juntamente com o professor de matemática”.

O relato destas ações possibilitou que professora em formação inicial, por meio da prática, mudasse suas ações, acarretando a descoberta de novas soluções para os 
problemas encontrados na sala de aula. Ao pensar criticamente sobre sua prática docente, a professora em formação inicial pôde elaborar novas estratégias e metodologias de ensino, coerentes com as novas situações encontradas.

Por meio do Processo de Reflexão Orientada e com as orientações da professora formadora, foi possível à professora em formação inicial confrontar as divergências existentes entre suas teorias explícitas e implícitas, proporcionando o desenvolvimento de concepções mais adequadas e a busca por melhorias em sua prática docente (Suart \& Marcondes, 2018; Peme-Aranega et al., 2009).

\section{Conclusões e Implicações}

Essa pesquisa buscou investigar como o processo de reflexão orientada contribuiu para que uma professora em formação inicial refletisse e buscasse melhorar sua prática docente. Ao participar do grupo de reflexão orientada, a futura professora teve a oportunidade de vivenciar ações associadas aos quatro contextos de Processo de Reflexão Orientada propostos por Abell e Bryan (1997). Ou seja, durante os encontros, ela pode discutir referenciais teóricos, diferentes práticas docente, compartilhar suas experiências com o grupo e ainda refletir sobre sua própria prática, revendo, constantemente, suas ações durante a elaboração da sequência, dos planos e da regência das aulas.

Destacamos que o desenvolvimento de atividades, planejamentos e estratégias promovidas no PRO, estavam centradas na abordagem do Ensino por Investigação, já que o grupo compreende que tal perspectiva contribuiu para o desenvolvimento de diversas habilidades essenciais para a formação de um indivíduo mais crítico diante das situações vivenciadas cotidianamente, sejam elas de cunho científico, social, ambiental, ético ou moral.

No entanto, planejar e desenvolver atividades nesta perspectiva se torna bastante complexo, principalmente para um professor em formação inicial, pois a atividade de investigação requer que o professor se torne um questionador e mediador da construção das ideias pelos estudantes, exigindo a coordenação de uma multiplicidade de habilidades e processos por parte dos futuros professores.

Nesta pesquisa, por exemplo, embora a professora em formação inicial tenha tido a oportunidade de participar de discussões e práticas relacionadas ao Ensino por Investigação, quando ela elabora os seus planos de aulas iniciais, acaba apenas mencionando os elementos do Ensino por Investigação, não desenvolvendo-os de forma a contemplar uma proposta com uma maior aproximação da abordagem. Assim, percebe-se que, muitas vezes, pode haver uma diferença entre suas concepções explícitas e implícitas (o que se diz e o que se faz), o que evidencia a importância de o futuro professor refletir sobre suas ações e práticas docentes, superando obstáculos para sua evolução profissional.

É neste sentido que o PRO parece contribuir para uma análise e reflexão mais orientada e crítica pelos futuros professores, ao relacionar teoria e prática. Isto é, quando a professora em formação inicial apresenta seus planos de aula para o grupo PRO, eles 
evidenciam lacunas com relação à abordagem do Ensino por Investigação, assim, a futura professora os reelabora, propondo questões para levantar ideias prévias dos estudantes, para desenvolver a questão problema e realizar a sistematização do conhecimento, que são considerados por Carvalho (2018) e Zômpero e Laburú (2011), elementos essenciais da abordagem de Ensino por Investigação.

Assim, por meio de um processo gradual de reflexão, seja por meio das reflexões individuais relatadas em seu diário de campo, ou das coletivas no grupo do PRO, a futura professora pôde repensar suas ações e promover processos reflexivos importantes para a tomada de consciência sobre as lacunas encontradas, que foram repensadas durante a reelaboração das atividades.

Além da reflexão constante sobre seus planejamentos e regência, outro aspecto bastante relevante proporcionado pelo PRO está na possibilidade de uma reflexão coletiva relacionada às primeiras experiências em sala de aula. Durante os encontros, a professora em formação inicial relatou imprevistos vivenciados, bem como seus conflitos, medos e receios durante a regência das aulas. A pesquisa realizada por Carvalho (2018) aponta que as aulas do Ensino Médio desenvolvidas na perspectiva do Ensino por Investigação, não vêm alcançando resultados satisfatórios, quando comparadas aos outros níveis de ensino. A autora destaca que um dos motivos para esses resultados, está no fato de, na maioria das vezes, o professor responsável pelas disciplinas de Química, Física ou Biologia ser o único professor que ministra tais disciplinas na escola e, assim, não pode contar com a colaboração de outro docente para compartilhar ideias e trocar experiências sobre uma nova estratégia ou abordagem de ensino e, também, sobre sua prática, suas crenças e seus anseios.

Nesta pesquisa, acreditamos que tal necessidade possa ser contemplada, já na formação inicial, por meio do grupo de reflexão. O PRO contribuiu para a futura professora construir e reconstruir suas ideias e refletir sobre as crenças, dilemas e conflitos enfrentados. Ainda, possibilitou trocas de experiências e o compartilhamento de suas dificuldades e anseios com outros colegas, reconhecendo que tais dificuldades vivenciadas não eram apenas suas, mas, também, reconhecidas pelos pares. Cabe ressaltar que os outros licenciandos e a professora formadora também auxiliaram para que a futura não ficasse presa somente aos problemas da sua regência e prática, mas valorizaram as diferentes ações realizadas por ela.

No entanto, para que o ambiente de coletividade e companheirismo entre os participantes do PRO seja favorecido, o papel do professor formador é de extrema relevância. Durante todo o processo aqui apresentado, a professora formadora não impõe suas ideias ou exige que a professora em formação inicial apresente os elementos pedagógicos essenciais que auxiliariam o desenvolvimento das atividades propostas por meio da abordagem de Ensino por Investigação. Ao contrário, a professora formadora promove uma relação de parceria entre ela e a futura professora, bem como com os outros professores do grupo que estão, auxiliando-os nas dificuldades encontradas, não julgando as ações ou ideias propostas ou emitindo juízo de valor acerca das dúvidas, 
ideias e ações. A professora formadora os coloca em conflito, com constantes indagações que os fazem repensar suas ideias, criando um ambiente que lhes dê tempo para reflexão e replanejamento cuidadoso, juntamente com um suporte, pedagógico e afetivo. Assim, o professor principiante não deve sentir-se obrigado a aceitar a opinião de outra pessoa só porque o professor ou professora formadora está em uma posição de autoridade (Alarcão, 2011).

Ainda, por meio da pesquisa ação reflexiva, mudanças e evoluções nas ideias da professora em formação inicial ficaram ainda mais claras, proporcionando a ela um novo ciclo de reestruturação nas suas concepções, potencializando a consciência sobre a sua prática, já que ela revisitou as suas ações e todo o processo vivenciado durante o $\mathrm{PRO}, \mathrm{o}$ que possibilitou a ela continuar a repensar de maneira significativa sua prática docente, buscando aperfeiçoá-la. Assim, evidencia-se a importância do processo reflexivo e da pesquisa ação, antes, durante e após o desenvolvimento de ações docentes.

Por meio das análises, salientamos, que mais encontros do PRO poderiam ter sido realizados, discutindo com maior ênfase, elementos pedagógicos como a questão problema e a sistematização, que foram os quais a professora em formação inicial apresentou maiores dificuldades nos planos e durante sua prática docente. Além disso, reuniões individuais entre a licencianda e a professora mediadora e, a leitura do diário de campo pela professora formadora, poderiam ter contribuído para que ela identificasse outras necessidades no processo formativo da professora em formação inicial e, também, propor novas leituras de referenciais para o grupo e questões relacionadas à prática docente. De acordo com Peme-Aranega e colaboradores (2009), encontros individuais são relevantes durante o PRO, de forma a individualizar o processo reflexivo.

Neste sentido, evidenciamos a importância de os cursos de formação inicial proporcionem momentos para que os futuros professores vivenciem e reflitam sobre novas abordagens de ensino, como o Ensino por Investigação, assim como, sobre suas próprias concepções acerca do processo de ensino e aprendizagem, de suas crenças, dilemas e conflitos.

Destaca-se que, embora a participação no PRO tenha exigido da professora em formação, de seus colegas e, também, da professora formadora, elevado envolvimento e tempo para o desenvolvimento, que podem ser apresentados como argumentos contrários a essa metodologia de formação, as ações relacionadas a esse processo formativo podem ser desenvolvidas no decorrer de toda a formação inicial dos futuros professores, por meio de um diálogo constante entre as disciplinas relacionadas ao Estágio Supervisionado e as disciplinas específicas da licenciatura, como as Práticas como Componente Curricular.

Por fim, reforçamos a relevância de as universidades possibilitarem que os futuros professores possam vivenciar processos formativos como o PRO, pois as dificuldades evidenciadas pela professora em formação inicial mostram algumas fragilidades dos cursos de formação de professores e, esses momentos, podem possibilitar que os licenciandos superem obstáculos e dificuldades relacionadas à prática docente e desenvolvam-se cada vez mais como profissionais críticos e reflexivos. 


\section{Referências}

Abell, S. K., \& Bryan, L. A. (1997) Reconceptualizing the elementary science methods course using a reflection orientation. Journal of Science Teacher Education, 8(3), 153166. https://doi.org/10.1023/A:1009483431600

Alarcão, I. (2011). Professores reflexivos em uma escola reflexiva. $8^{\text {a }}$ edição. Editora Cortez.

Bardin, L. (2016). Análise de Conteúdo. Edições 70.

Barreiros, G. B., \& Gianotto, D. E. P. (2016). O diário de aula como instrumento de reflexão na formação inicial de professores de ciências biológicas. Formação DocenteRevista Brasileira de Pesquisa sobre Formação de Professores, 8(15), 33-56. https://doi. org/10.31639/rbpfp.v8i15.140

Bryan, L. A., \& Recesso, A. (2006). Promoting reflection among science student teachers using a web-based video analysis tool. Journal of Computing in Teacher Education, 23(1), 31-39.

Burhan-Horasanl1, E., \& Ortaçtepe, D. (2016). Reflective practice-oriented online discussions: A study on EFL teachers' reflection-on, in and for-action. Teaching and Teacher Education, 59, 372-382. https://doi.org/10.1016/j.tate.2016.07.002

Cachapuz, A., Praia, J., \& Jorge, M. (2002). Ciência, educação em ciência e ensino das ciências. (Temas de investigação, 26). Ministério da Educação, Lisboa, 2002

Carvalho, A. M. P. (2018). Fundamentos teóricos e metodológicos do ensino por investigação. Revista Brasileira de Pesquisa em Educação em Ciências, 18(3), 765-794. https://doi.org/10.28976/1984-2686rbpec2018183765

Carvalho, A. M. P. D. (2013). Ensino de Ciências e a proposição de sequências de ensino investigativas. In A. M. P. de Carvalho (Org) São Paulo: Cengage Learning, (1-20).

Delizoicov, D., Angotti, J. A., \& Pernambuco, M. M. C. A. (2018). Ensino de Ciências: fundamentos e métodos. Cortez.

Fernandez, C. (2018). Formação de professores de Química no Brasil e no mundo. Estudos Avançados, 32(94), 205-224. https://doi.org/10.1590/s0103-40142018.3294.0015

Freire, P. (2014). Pedagogia da autonomia: saberes necessários à prática educativa. Paz e Terra.

Gauthier, C., Martineau S., Desbiens, J. F, Malo, A., \& Simard, D. (2013). Por uma teoria da pedagogia: pesquisas contemporâneas sobre o saber docente. Unijuí.

Gil-Pérez, D., \& Vilches, A. (2006). Educación Ciudadana y alfabetización científica: mitos y realidades. Revista Iberoamericana de educación, 42(1), 31-53. https://doi. org/10.35362/rie420760 
Kayapinar, U. (2018). Reflection in Language Teaching: A Comparison between Preservice and Experienced Teachers of English. Educational Research and Reviews, 13(23), 754-763. https://doi.org/10.5897/ERR2018.3619

Maldaner, O. A. (2013). A formação inicial e continuada de professores de química: professores/pesquisadores. Unijuí.

Marcondes, M. E. R., do Carmo, M. P., Suart, R. C., da Silva, E. L., Souza, F. L., Santos Jr, J. B., \& Akahoshi, L. H. (2009). Materiais instrucionais numa perspectiva CTSA: uma análise de unidades didáticas produzidas por professores de química em formação continuada. Investigações em Ensino de Ciências, 14(2), 281-298.

Mellado, V. (1998). The classroom practice of preservice teachers and their conceptions of teaching and learning science. Science education, 82(2), 197-214. https://doi. org/10.1002/ (SICI)1098-237X(199804)82:2<197::AID-SCE5>3.0.CO;2-9

Miranda, M. de S., Marcondes, M. E. R., \& Suart, R. de C. (2015). Promovendo a alfabetização científica por meio de ensino investigativo no ensino médio de química: contribuições para a formação inicial docente. Ensaio Pesquisa em Educação em Ciências, 17(3), 555-583. https://doi.org/10.1590/1983-21172015170302

Moate, J., Hulse, B., Jahnke, H., \& Owens, A. (2019). Exploring the material mediation of dialogic space - A qualitative analysis of professional learning in initial teacher education based on reflective sketchbooks. Thinking Skills and Creativity, 31, 167-178. https://doi. org/10.1016/j.tsc.2018.12.003

Nascimento, R. D., \& Gomes, A. D. T. (2018). A Relação entre o Conhecimento Conceitual e o Desempenho de Estudantes em Atividades Investigativas. Revista Brasileira de Pesquisa em Educação em Ciências, 18(3), 935-965. https://doi.org/10.28976/19842686rbpec2018183935

Oliveira, A. L., \& Tiyomi Obara, A. (2018). O ensino de ciências por investigação: vivências e práticas reflexivas de professores em formação inicial e continuada. Investigações em Ensino de Ciências, 23(2), 65-87. https://doi.org/10.22600/1518-8795. ienci2018v23n2p65

Oliveira, I., \& Serrazina, L. (2002). A reflexão e o professor como investigador. Reflectir e investigar sobre a prática profissional, 29, 29-42.

Peme-Aranega, C., Mellado, V., De Longhi, A. L., Moreno, A., \& Ruiz, C. (2009). La interacción entre concepciones y la práctica de una profesora de Física de nível secundario: Estudio longitudinal de desarrollo profesional basado en el proceso de reflexión orientada colaborativa. Revista electrónica de enseñanza de las ciencias, 8(1), 283-303.

Sasseron, L. H. (2015). Alfabetização científica, ensino por investigação e argumentação: relações entre ciências da natureza e escola. Ensaio Pesquisa em Educação em Ciências (Belo Horizonte), 17(spe), 49-67. http://dx.doi.org/10.1590/1983-2117201517s04 
Sasseron, L. H., \& de Carvalho, A. M. P. (2008). Almejando a alfabetização científica no ensino fundamental: a proposição e a procura de indicadores do processo. Investigações em ensino de ciências, 13(3), 333-352.

Solino, A. P. (2017). Tese (Doutorado em Educação), Problemas potenciais significadores em aulas investigativas: contribuições da perspectiva histórico-cultural. Faculdade de Educação da Universidade de São Paulo. São Paulo, SP.

Suart, R. de C., Silva, R. A. da, Silva, F. N. da, \& Souza, J. A. de. (2018). 1 B135 Planos de aulas e o diário de campo: estratégias para a formação inicial docente. Tecné, Episteme $Y$ Didaxis: TED, (Extraordin). https://revistas.pedagogica.edu.co/index.php/TED/article/ view/8886

Suart, R. de C., \& Marcondes, M. E. R. (2018). O processo de reflexão orientada na formação inicial de um licenciando de química visando o ensino por investigação e a promoção da alfabetização científica. Ensaio Pesquisa em Educação em Ciência, 20, e9666. https://doi.org/10.1590/1983-21172018200106

Tripp, D. (2005) Pesquisa-ação: uma introdução metodológica. Educação e pesquisa, 31(3), 443-466. https://doi.org/10.1590/S1517-97022005000300009

Wartha, E. J., \& Faljoni-Alário, A. (2005). El concepto de contextualización presente en los libros de texto de química brasileños. Educación química, 16(1), 151-158. http:// dx.doi.org/10.22201/fq.18708404e.2005.4e.66079

Zabalza, M. A. (2004). Diários de Aula: um instrumento de pesquisa e desenvolvimento pessoal.Trad. de Ernani F. Rosa. ArtMed.

Zeichner, K. M. (2008). Uma análise crítica sobre a reflexão como conceito estruturante na formação docente. Educação \& Sociedade, 29(103), 535-554. https://doi.org/10.1590/ S0101-73302008000200012

Zômpero, A. F., \& Laburú, C. E. (2011). Atividades investigativas no ensino de ciências: aspectos históricos e diferentes abordagens. Ensaio Pesquisa em Educação em Ciências, 13(3), 67-80. https://doi.org/10.1590/1983-21172011130305

Zômpero, A. F., Figueiredo, H. R. S., \& Garbim, T. H. (2017). Atividades de investigação e a transferência de significados sobre o tema educação alimentar no ensino fundamental. Ciência \& Educação (Bauru), 23(3), 659-676. https://doi.org/10.1590/1516731320170030008 


\section{Raniele Aparecida da Silva}

https://orcid.org/0000-0002-4406-6672

Universidade de São Paulo Instituto de Química

São Paulo, São Paulo, Brasil ranieleaparecidasilva@gmail.com

Francislainy Natália da Silva

https://orcid.org/0000-0003-4117-3752

Universidade Federal de Lavras

Departamento de Química Lavras, Minas Gerais, Brasil francislainysilva@gmail.com

Rita de Cássia Suart

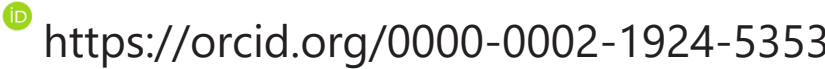

Universidade Federal de Lavras

Departamento de Química Lavras, Minas Gerais, Brasil ritasuart@ufla.br

Submetido em 05 de maio de 2020

Aceito em 04 de setembro de 2020

Publicado em 16 de novembro de 2020 